In implementing team-based learning in a purely online, asynchronous course, the authors advise planning early and planning well, a process for which they provide specific advice.

\title{
Team-Based Learning in Asynchronous Online Settings
}

\author{
Sunay Palsolé, Carolyn Awalt
}

Team-based learning (TBL) has been shown to improve student learning in a variety of settings (Michaelsen, Knight, and Fink, 2004). In a majority of cases, team-based learning (TBL) has been implemented in face-to-face formats and occasionally in blended learning formats, which are partially online partially and face-to-face in a classroom (Freeman, 2004). The Sloan Consortium surveys (Allen and Seaman, 2007) report a steady increase in the enrollments in online courses, and this is borne out by data gathered at the University of Texas at El Paso. Over the past five years, we have faced an increase in the demand for courses in flexible learning formats (blended and 100 percent online), with enrollment increasing by an average of 20 percent each year. With the unequivocal efficacy of TBL in the traditional face-to-face class format, it became imperative to find a way to implement it in flexible learning format courses. This chapter describes the implementation of asynchronous TBL in a fully online course and provides some practical strategies for practitioners interested in such implementations.

Keeping the four basic principles of TBL in mind (see Chapter One) during the design process, we first implemented TBL strategies in a fully online course in fall 2005 using a combination of testing and synchronous chat tools. Table 7.1 gives the equivalencies in the online environment of processes that are usually followed in a face-to-face environment.

The course that we redesigned for online delivery using TBL was a large undergraduate course with an enrollment of approximately about $110 \mathrm{stu}-$ dents. Although this new teaching strategy seemed to work after students 


\section{Table 7.1. Equivalencies of Face-to-Face to Online Class Activities}

Traditional Face-to-Face Class

Preclass preparation (usually assigned textbook readings)

Multiple-choice individual readiness assurance tests (iRat) using Scantrons

Team readiness assurance tests (tRAT) with immediate feedback assessment technique forms

Mini lecture based on RAT results.

Five to seven RATs per courseto prepare for application activities; may be followed by a peer evaluation

Grading of team application activities typically done by instructor and may include evaluations from other teams; individual scores may be modified base on a postactivity peer evaluation. 20 percent $=$ peer evaluation .

Often includes an end-of-semester reflective assignment.
Online Class

Assigned readings from books, Web sites, discovery questions, and so forth.

Multiple-choice iRAT using online testing tools.

tRAT based a discussion board over two days. Team leader (assigned in advance on a rotating basis) compiles answers and submits team answers. Team reporter compiles discussion and posts gist of the discussion to the common board. Feedback on RAT.

Mini lecture based on RAT results and discussion is added to the week's lecture.

Five RATs in weeks 3, 6, 9, 12, and 15. Schedule matches the stages of the team project, which is due at the end of the semester. Peer evaluations are done after each RAT on an Excel spreadsheet that each individual uploads as an assignment.

Team projects are graded as follows: 50 percent $=$ individual grade (by instructor's assessment of contribution on assignment using a rubric that was created by team); 30 percent $=$ team grade;

End of semester is wrapped up with a reflective assignment.

became accustomed to the timetables, we had increasing complaints from students about finding convenient times required to work synchronously for taking the individual and team readiness assurance tests (respectively, iRATs and tRATs). Given the fact that most students tend to take fully online courses for the time and space flexibility afforded to them, it became necessary to find a solution to doing TBL in asynchronous modalities.

A revised version of asynchronous TBL was implemented in fall 2006 with a follow-up in fall 2007. The 2006 course, Interdisciplinary Technology and Society, had an enrollment of seventy-four students. We decided to leverage the capability of instant feedback by using the built-in test tools in our learning management system and the fact that we could elicit thoughtful responses (Markel, 2001; Freeman, 2004, Palloff and Pratt, 2005) from the students using the discussion board tool. We also took into account that 
time expands in online discussions (Meyer, 2003) and designed the learning process to account for this.

Our first design revisions were focused on modifying our procedures to promote team cohesion better. Then, before we launched the actual course, we refined the procedures based on feedback from four runthroughs with student workers playing the part of students.

\section{Setup}

One of the most important things to keep in mind when teaching online courses is that you cannot expect students to be able to find matching times for synchronous work, and this is particularly true when they are taking online courses that are designed specifically to afford them time and space flexibility. Nevertheless, tasks can be designed to achieve the desired student engagement provided that extra time is incorporated to enable team interactions to occur.

To allow students extra time, we required learning teams to post to the discussion board every week and provide thoughtful feedback to every member of the team. This established the expectation on the part of the students that discussion was an important part of the class. We then set up teams to participate in TBL exercises. We explained to the students why TBL was important and the exact procedures that would be followed.

Creating Teams. We chose to create five-member teams using the automated tool in our learning management system. Three semesters of study convinced us that automated team selection created team assignments that were just as diverse as, and sometimes more diverse than, those created by manual processes used by the instructor and saved time overall. Teams were permanent and were not allowed to change. We asked teams to create their own team contracts and establish their strategy for working together. To have teams discover their team assets, we had them post introductions of themselves with their strengths and weaknesses and their overall goals for the class in their team discussion board, which is somewhat similar to Salmon's five-stage framework (2003). Borrowing from Harasim, Hiltz, Teles, and Turoff (1995) the idea that students working in a virtual environment need to discover common goals and objectives to be successful, we then asked the team members to look at each other's strengths and weaknesses and outline what they would do to build a support structure. We asked each team to write this up as a formal support document and post it in their team files area in WebCT.

Creating Accountability. We created multiple-choice tests using the learning management system's built-in test and assessment tools. Multiplechoice tests were duplicated so they could be used by the individual students to ensure accountability for individual preparation and for the tRAT after the team's discussion in its discussion board. Each team activity was followed by a peer evaluation carried out using a spreadsheet provided to the team or a tool built at the University of Texas at El Paso specifically for 
that purpose and uploaded by each team as an assignment. In the case of the spreadsheet, grades were tallied using macros.

Promoting Team Learning and Development. Our previous experience and research demonstrates that engaging learners in the online collaborative environment requires that all teams (and members) must feel that their ideas are being heard and discussed (McConnell, 2006). To generate this engagement and to promote team development, we created a system of sharing and voting for the best team projects. Team products were shared in a discussion or drop box area, and every member of the class voted on the best product (they could not vote for their own team) and provided feedback. The results were tallied, and the winning team was awarded extra points that amounted to about 5 percent of the final project grade. This is done so there is enough incentive for teams to do well, but not so much as to bring in the factor of greed. We also added a reflection assignment that teams turned in every four weeks. For this assignment, they examined their goals set at the beginning of the class and evaluated whether they were on target. We spent significant time writing questions that were indirect and open-ended queries. For example, we asked them to think about the philosophy of technology use on the El Paso-Juarez border instead of asking them to list what technologies were being used on the El Paso-Juarez border area.

Providing Frequent and Immediate Feedback. The automation of the test tool in the learning management system helped provide feedback fairly instantaneously when team leaders entered the team answers on the tRAT. Due to the nature of online work, team leaders rotated each session and were responsible for taking the tRAT based on the discussions of the assigned questions in the team discussion board. Although the teams were not present in the same space at the same time, the students' excitement in wanting to know their performance was demonstrated by the fact that most of the students checked the group grades within twenty-four hours of the team leader's submitting the team answers. We also wrote learning management system rules to allow the release of scores for the iRATs only after the team leaders had completed the tRAT. We provided feedback on the team discussion boards following completion of the tRAT. We used the discussion boards to suggest topics for our mini lectures that were created and added to the course content as a result of the students' performance on the RATs. An overview of our adaptation of the RAT to online environment appears in Figure 7.1.

How We Implemented the 4 S's. The final project was a team project and required students to look at the City of El Paso and work out changes that may need to be done (within reason) to build a sustainable ecology. We had students and teams complete five application assignments and tried to keep the 4 S's of effective team assignments in doing so: significant to students, same problem, specific choice, and simultaneous report (see Chapter One and the volume appendix). Furthermore, each assignment was designed to build up the knowledge needed to complete the final project. 
Figure 7.1. The Readiness Assurance Process
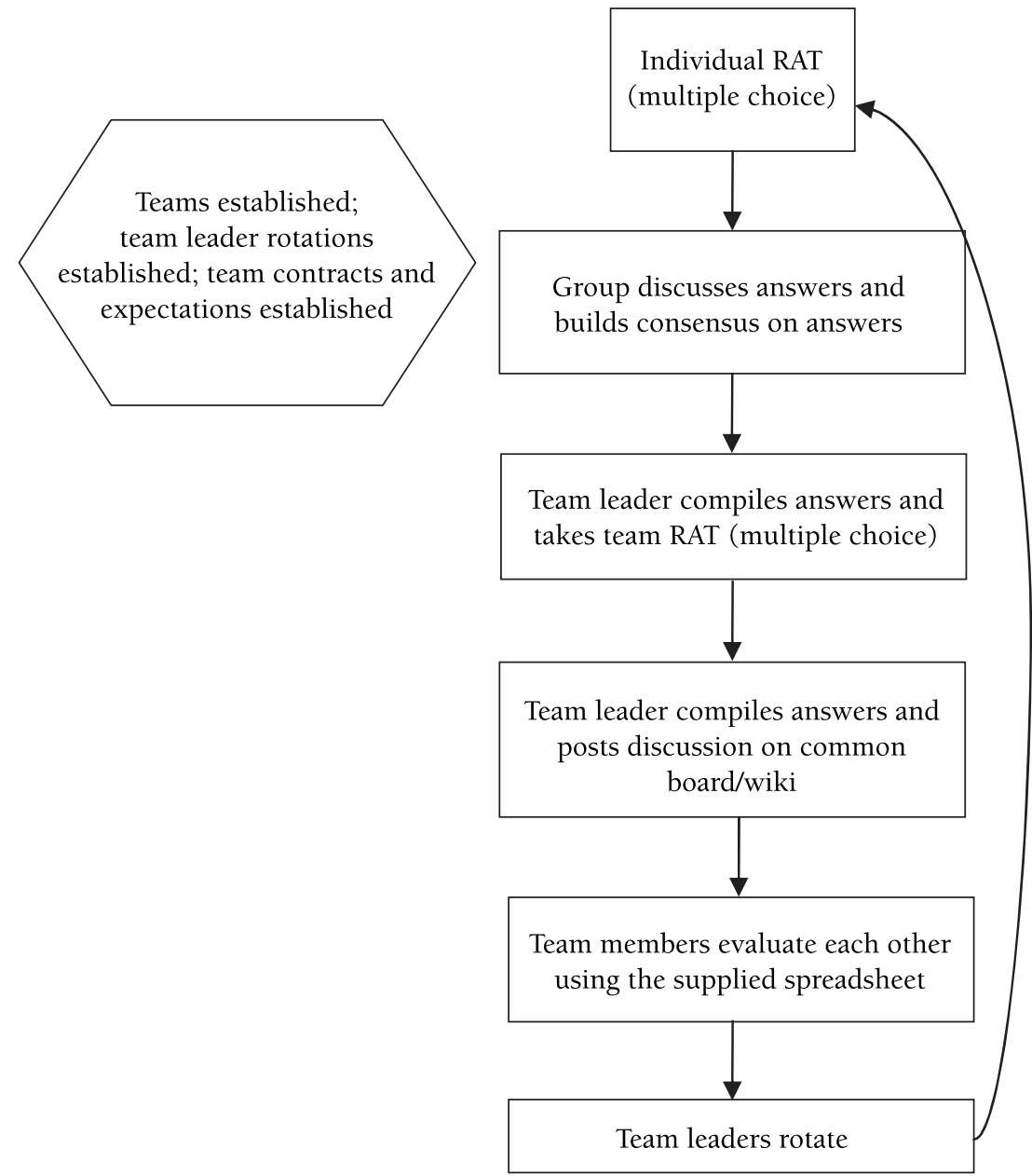

Note: Completion of the individual and team RATs takes about three to four days from start to finish. Source: Michaelsen, Michaelson, and Black (1994). Adapted to the Online Course Environment.

Assignments were made available to all the teams at the same time on a common discussion board. An example assignment follows (significant to students):

What types of renewable and alternative energy technologies will promote economic growth for a sustainable environment for the 21 st century? Isolate some of the issues, support your arguments with specific references, and outline some possible solutions. Use the evaluation framework you developed in the previous assignment to help guide your solution path. 
Each team had the same assignment (same problem) and the same time frame to turn in their work:

Day 1 Assignment is posted to a common discussion board.

Days 1-5 Team discussion, consensus building, and development of final product on Team Wiki.

Day 6 Team assignment submitted to the grading tool and posted to its discussion board. Teaching team collects discussions and posts them to the common discussion board for all teams to see (simultaneous reporting).

Days 6-7 Team members fill out peer evaluation forms using the spreadsheet or online tool.

We did not implement the $4 \mathrm{~S}$ of specific choice, since we did not think we could do this effectively. In the process of writing this chapter and discussions about the process, however, we have realized that we can implement specific choice by presenting the teams with a list of technologies and then having them choose one or a combination from the presented list. This process will be implemented in spring 2009.

We found that even when we did not have synchronous or face-to-face simultaneous reporting, the students were still excited to see what their grades were and the solutions that the other teams had produced. This was indicated by their checking their individual and team grades and seeing what other teams had come up with and posting comments about the work that the other teams had produced.

\section{Outcomes}

We measured our outcomes by looking at the overall student performance, retention rates, and student satisfaction with TBL. The results are discussed following.

Student Performance. Overall, the students performed well in our online team-based learning class. The exception was two teams that had below-average performances. We could predict the success rates of the teams by tracking the number of posts they had in the team discussion boards and also how engaged each of the team members was in looking at the products of the other teams.

Student Retention. One of the main issues commonly seen in online courses is that they face a higher rate of student attrition as compared to a traditional classroom. In both courses that implemented TBL, we realized about a 90 percent retention rate. We feel that this was achieved by helping the students set goals and reflect on them throughout the semester and the fact that being part of a functioning team helped build the right support structure to help them stay on track even if they fell a little behind at times. 
Student Comments on TBL. Students were also asked to engage in a reflective exercise that asked them to think about what they had achieved in the class through teamwork and how each step contributed to their success. We also surveyed the students at the end of the semester about class effectiveness. Among their comments were these:

"It was a pain to keep doing the evaluations but I think it helped because no one could hide so everyone had to do the work."

"I had never thought that teams would work well online. I think it was interesting to do the weekly postings and exchange views."

"I won't say that I enjoyed the team learning, but this was the best experience I had working in teams."

"It was a good experience. I liked reading other teams' work and the competition. I just wish we had done better."

An overall evaluation of the class did not show any significant differences in grades compared to the face-to-face strategy, but there was significant satisfaction with teamwork when students were asked to compare their experiences in other classes where they worked in formal or informal teams.

\section{Conclusion}

Given the overall performance, experience, and feedback from the students, we feel that our adaptation of TBL in the online course was a success. Some factors that we believe contributed to the success are an early team-building exercise that helped the teams identify strengths and weaknesses and build a support structure and frequent peer evaluations that helped keep the teams on track. This was very important since the teams did not have a chance to meet, so receiving frequent feedback on their individual contributions to the team did contribute to team success. In addition, the team competition helped create interteam excitement for the best finished product, and the fact that the best-performing team was selected by its peers was a great contributing factor in the success of the teams.

The team assignments were designed to cascade into each other and used products from previous assignments for the next assignment. This sequencing was a little difficult to do, but it was valuable to help the teams see the pathway to the big picture final product.

Overall we realized that the teams needed a lot of training in the beginning about Netiquette if they were to succeed well without misinterpreting responses given to queries. Moreover, it became apparent that while most aspects of classical TBL can be implemented in online formats, the procedures for the readiness assurance process and application exercises have to be modified to fit the online environment.

Finally, applying the TBL strategy in an online environment was a timeconsuming task to develop and implement the first time, but the overall 
results of the student satisfaction surveys made it a worthwhile and successful enterprise.

\section{Next Steps}

Student feedback indicated that they valued their experiences with team building in the online courses. They also indicated that the spreadsheet evaluation tool was preferable to the online tool (which was easier to use) because it let them evaluate each other on much broader criteria. We plan to examine newer tools that have been developed for online peer evaluations and the readiness assurance processes to see if they can be used to simplify these processes.

We have these tips for adoption:

- Plan early and plan well. Map out the entire course flow using software or a whiteboard. We found this to be valuable as we built each of the assignments and worked out submission dates and times to create as seamless a process as possible.

- Design for a few weeks, and have the material tested by students or colleagues to iron out any wrinkles in directions or plans.

- Work out a calendar, and have a third party double-check it.

- Provide as many details as possible. If there is a misinterpretation to be made, it will be made in the online environment.

- Create flowcharts for the process, and post them in the syllabus. They help students keep track of the processes.

- Provide another assignment checklist outside the syllabus or schedule, and post reminders online.

- Conduct an early team-building exercise that has low stakes and helps teammates get to know each other.

- Be prepared in the first two weeks to answer endless queries about the work details in the class. Post a frequently asked questions list in the course.

- Set up a help board in the discussion area for the class, and encourage students to post queries to the help board first, before e-mailing you, so you can reply once and point other students to the same area.

- Encourage students to help their peers, and provide some incentive to do so.

- Be prepared to modify plans as needed. We found this to be particularly true when assigning peer evaluations. We modified the number of evaluations when circumstances dictated.

- Add a reflection paper toward the end of the semester to help bring all the work done in the class using TBL back into focus.

\section{References}

Allen, E., and Seaman, J. Online Nation: Five Years of Growth in Online Learning. Needham, Mass.: Sloan Consortium, 2007. Retrieved June 2, 2008, from http://www.sloanc.org/publications/survey/index.asp. 
Freeman, M. "Team-Based Learning in a Course Combining In-Class and Online Interaction." In L. K. Michaelsen, A. B. Knight, and L. D. Fink (eds.), Team-Based Learning: A Transformative Use of Small Groups. Sterling, Va.: Stylus, 2004.

Harasim, L., Hiltz, S. R., Teles, L., and Turoff, M. Learning Networks: A Field Guide to Teaching and Learning Online. Cambridge, Mass.: MIT Press, 1995.

Markel, S. "Technology and Education Online Discussion Forums: It's in the Response." Online Journal of Distance Learning Administration, Summer 2001, 4(2). Retrieved June 2, 2008, from http://www.westga.edu/\%7Edistance/ojdla/browsearticles.php.

McConnell, D. E-Learning Groups and Communities. Bristol, Pa.: Open University Press, 2006.

Meyer, K. A. "Face-to-Face Versus Threaded Discussions: The Role of Time and HigherOrder Thinking." Journal of Asynchronous Learning Networks, 2003, 7(3), 55-65.

Michaelsen, L. K. "Getting Started with Team-Based Learning." Retrieved June 1, 2008, from http://www.ou.edu/pii/teamlearning/docs/Getting\%20Started\%20with\%20TBL. pdf.

Michaelsen, L. K., and Black, R. H. "Building Learning Teams: The Key to Harnessing the Power of Small Groups in Higher Education." In S. Kadel and J. Keehner (eds.), Collaborative Learning: A Sourcebook for Higher Education. State College, Pa.: National Center for Teaching, Learning and Assessment, 1994.

Michaelsen, L. K., Knight, A. B., and Fink, L. D. Team-Based Learning: A Transformative Use of Small Groups. Sterling, Va.: Stylus, 2004.

Palloff, R. M., and Pratt, K. Lessons from the Cyberspace Classroom: The Realities of Online Teaching. San Francisco: Jossey-Bass. 2001.

Salmon, G. Etivities: The Key to Active Online Learning. London: Kogan Page, 2003.

SUNAY PALSOLE is the director of instructional support at the University of Texas at El Paso.

CAROLYN AWALT is an assistant professor in the college of education and the advisor for the Online Alternative Teachers Certificate Program. 